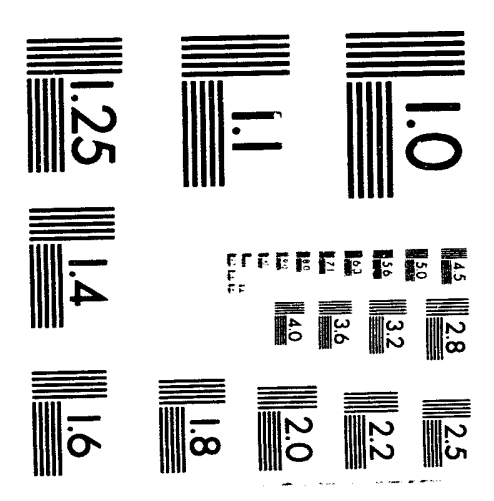



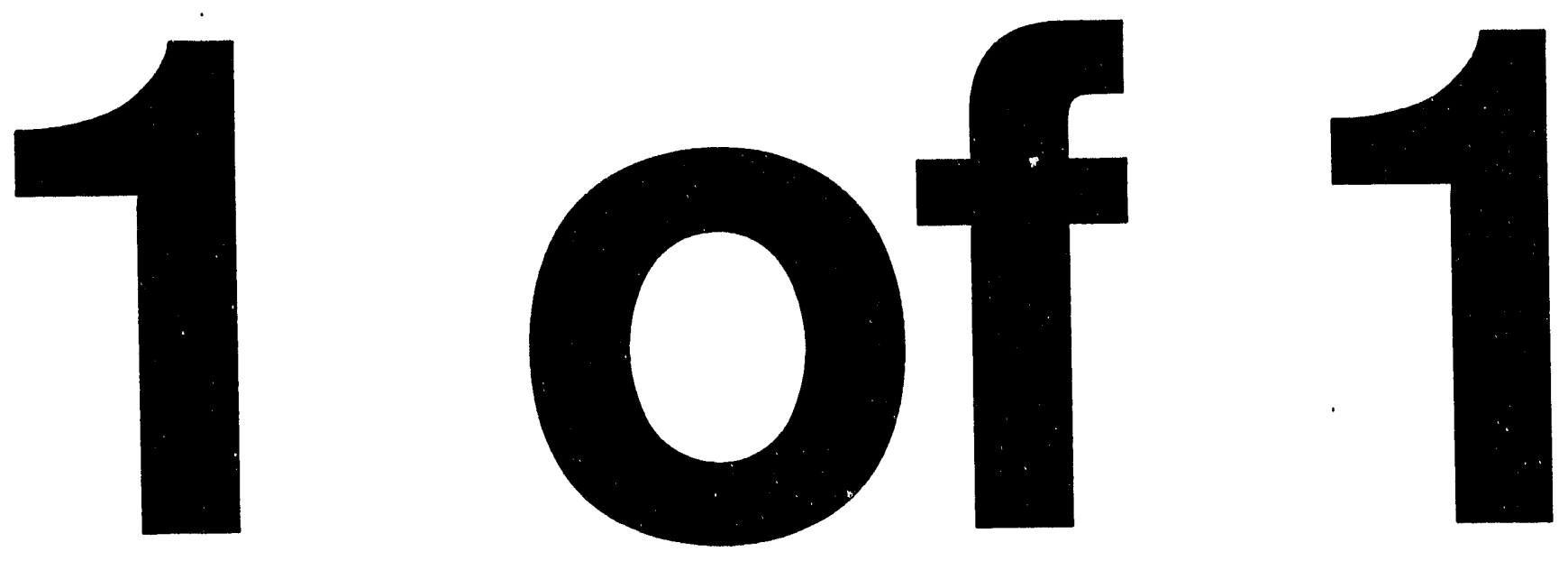


\title{
EXTENDED-RANGE ORDER IN GLASSES
}

\author{
Adam J. G. Ellison, David Long Price, Marie-Louise Saboungi \\ Materials Science Division \\ Argonne National Laboratory \\ Argonne, IL 60439
}

\author{
Takeshi Egami, Rui-Zhong Hu \\ University of Pennsylvania \\ Philadelphia, PA 19104 \\ W. Spencer Howells \\ Rutherford-Appleton Laboratory \\ Chilton, Didcoi \\ Oxfordshire OX11 OQX \\ United Kingdom
}

$/ \mathrm{sm}$

The submitted manuscript has been authored by a
contractor of the U.S. Government under contract No.
W-31-109-ENG-38. Aocondingly, the U.S. Government
retains a nonexclusive, royalty-iree Ikense to publish
or reproduce the published form of this contribution, or
allow others to do so. for U.S. Government purposes.

\section{DISCLAIMER}

This report was prepared as an account of work sponsored by an agency of the United States This report was prepared as an account of work spent nor any agency thereof, nor any of their employees, makes any warranty, express or implied, or assumes any legal liability or responsibility for the accuracy, completeness, or usefulness of any information, apparatus, product, or process disclosed, or represents that its use would not infringe privately owned rights. Reference herein to any specific commercial product, process, or service by trade name, trademark, manufacturer, or otherwise does not necessarily constitute or imply its endorsement, recommendation, or favoring by the United States Government or any agency thereof. The views and opinions of authors expressed herein do not necessarily state or reflect those of the United States Government or any agency thereof.

\section{Distribution:}

1-2. M. J. Masek

3. B. D. Dunlap

4. M. B. Brodsky

5. J. D. Jorgensen

6. B. S. Brown

7. Editorial Office

8. Authors

This work is supported by the U.S. Department of Energy, Basic Energy Sciences, Materials Sciences, under contract No. W-31-109-ENG-38. 


\section{Extended-Range Order in Glasses}

Adam J. G. Ellison, David Long Price, Marie-Louise Saboungi

Argonne National Laboratory

Argonne, Illinois 60439

Takeshi Egami, Rui-Zhong Hu*

University of Pennsylvania

Philadelphia, Pennsylvania 19104

W. Spencer Howells

Rutherford-Appleton Laboratory,

Chilton OX11 OQX, U.K. 


\title{
Extended-Range Order in Glasses
}

Adam J. G. Ellison, David Long Price, Marie-Louise Saboungi

Argonne National Laboratory

Argonne, Illinois 60439

Takeshi Egami, Rui-Zhong $\mathrm{Hu}^{*}$

University of Pennsylvania

Philadelphia, Pennsylvania 19104

W. Spencer Howells

Rutherford-Appleton Laboratory

Chilton OX11 OQX, U.K.

\begin{abstract}
A new type of order is identified in complex glasses. characterized by diffraction peaks at values of the wave vector below those typical of intermediate-range order. Combined neutron and anomalous $x$-ray diffraction studies of one glass exhibiting this behavior, vitreous rubidium germanate, indicate it to be associated with chemical ordering of the two cations with respect to each other.
\end{abstract}


The origin of intermediate-range order (IRO) in glasses is one of the outstanding problems in solid state physics. ${ }^{1}$ Indirect evidence of IRO is seen in the boroxyl stretching mode in the Raman spectra of borate glasses ${ }^{2}$ and perhaps in the so-called "defect" modes in $\mathrm{v}-\mathrm{SiO}_{2}{ }^{3}$ and the "companion" mode in $\mathrm{GeSe}_{2}{ }^{4}$ The most general and persistent evidence of IRO in glasses, however, is the so-called first sharp diffraction peak (FSDP), the low-Q feature in the average structure factor $S(Q)$ of most simple oxide and chalcogenide glasses.5 The FSDP is distinguished from other features in $S(Q)$ in that the product of its wave vector $Q_{1}$ and the nearest-neighbor distance is almost universally found to lie in the range 2.2-2.8.6 This implies correlation lengths $I_{1}$ $\sim \frac{2 \pi}{Q_{1}} \sim 2.5 r_{1}$. The origin of the FSDP in glasses is controversial: it has been variously attributed to the presence of layer-like structures in the glass 7 , to random packing of appropriate structural motifs 5 , and recently to a chemical ordering of voids and cations in oxide and chalcogenide glasses. 8 A correlation between the position of the FSDP and the low-frequency phonon spectrum has also been noted. ${ }^{9}$ Regardless of its origin, the FSDP clearly represents a type of IRO with a correlation length greater than the dimension of the nominal building blocks of oxide and chalcogenide glasses, for example $\mathrm{Si}\left(\mathrm{O}_{1 / 2}\right)_{4}$ tetrahedra in $\mathrm{v}-\mathrm{SiO}_{2}$.

The FSDP is not always, however, the first feature in the $S(Q)$ of a glass, nor does it necessarily represent the greatest correlation length in glasses. Recently obtained results from neutron and $\mathrm{x}$-ray diffraction from multicomponent germanate and silicate glasses show clear evidence of structure extending well beyond the correlation length $l_{1}$ typical of the FSDP. We p:esent neutron and $x$-ray diffraction data for one such system, $\mathrm{Rb}_{2} \mathrm{O}-\mathrm{GeO}_{2}$ glasses, and briefly discuss results for some other systems. 
Vitreous $\mathrm{GeO}_{2}$ was prepared by heating $99.999 \% \mathrm{GeO}_{2}$ (Cerac) at $1600^{\circ} \mathrm{C}$ for $18 \mathrm{hr}$ in a $\mathrm{Pt}$ crucible, then removing the crucible and placing it upon a massive $\mathrm{Cu}$ block. $\mathrm{Rb}_{2} \mathrm{O}-\mathrm{GeO}_{2}$ glasses were prepared in $100 \mathrm{~g}$ batches by splat quenching their melts from $1600^{\circ} \mathrm{C}$. For the neutron experiments, $\sim 10 \mathrm{~g}$ of a glass was pulverized under Ar, packed into a vanadium can, and capped with a gas-tight cap, thereby minimizing the possibility of surface contamination on these very hygrosçopic glasses. For the $x$-ray measurements, the samples were cast as flat plates, glued onto Al frames and lapped to give a smooth surface (roughness $<50 \mu$ ). Neutron diffraction measurements were made on $\left(\mathrm{Rb}_{2} \mathrm{O}_{0.2^{\bullet}}\left(\mathrm{GeO}_{2}\right)_{0.8}\right.$ glass at the SANDALS instrument at ISIS, RutherfordAppleton Laboratory, U.K. and on $v-\mathrm{GeO}_{2}$ and $\left(\mathrm{Rb}_{2} \mathrm{O}\right)_{x} \cdot\left(\mathrm{GeO}_{2}\right)_{1-x}$ for $x=0.1,0.2$ and 0.33 at the new GLAD instrument at IPNS, Argonne National Laboratory. Samples were run at ambient temperature for 8-10 hours each. Scattering from the $\mathrm{V}$ cans and the instrument background were also measured. Corrections were performed for absorption, multiple scattering, and inelasticity. Absolute normalization of the structure factors were obtained using a vanadium rod as an incoherent isotropic scatterer.

The average structure factors $S(Q)$ derived from the GLAD data for the four glasses are shown in Fig. 1. The first feature in the structure factor of $v$ $\mathrm{GeO}_{2}$ is a maximum at $\mathrm{Q}_{1} \sim 1.54 \AA^{-1}$ : using $\mathrm{r}_{1}=1.74$ from Ref. 10 , we obtain $Q_{1} r_{1} \sim 2.68$ for $v-\mathrm{GeO}_{2}$, clearly identifying this feature as the FSDP. The correlation length associated with IRO in $v-\mathrm{GeO}_{2}$ is thus $I_{1} \sim 4-5 \AA$, considerably larger than the dimension of the $\mathrm{Ge}\left(\mathrm{O}_{1 / 2}\right)_{4}$ tetrahedron or the distances between them $\left(r_{G e G e}-3.17 \AA\right)$

On the addition of the modifier $\mathrm{Rb}_{2} \mathrm{O}$ to the $\mathrm{GeO}_{2}$ network, however, the FSDP is no longer the lowest peak. Instead, a new feature arises at $Q_{0}=0.9 \AA$, implying a correlation length $\mathrm{I}_{\mathrm{O}} \sim 7 \AA$, larger than any correlation length reported 
up to now from diffraction studies of oxide glasses. We refer to this new feature as the "extended-range" order peak (EROP).

The behavior of the extended-range order peak (EROP) with increasing $\mathrm{Rb}_{2} \mathrm{O}$ content contrasts with the behavior seen for the FSDP. The FSDP moves to higher $Q$ but still remains within the range of its typical values in oxide and chalcogenide glasses. The EROP, in contrast, remains at the same position. The FSDP becomes less intense with increasing $\mathrm{Rb}_{2} \mathrm{O}$ concentration $\mathrm{x}$, whereas the intensity of the EROP increases up to $x=0.2$ and then decreases for larger $x$. Thus, the addition of a small amount of $\mathrm{Rb}_{2} \mathrm{O}$ produces extendedrange order, but this order starts to break down as the $\mathrm{Rb}_{2} \mathrm{O}$ concentration is increased further.

The EROP also appears in the x-ray diffraction patterns of these glasses. Fig. 2 compares raw diffraction data (corrected for dead-time and incident flux but not multiple or Compton scattering or absorption) for $\mathrm{v}-\mathrm{GeO}_{2}$ taken at an $\mathrm{x}$ ray energy $E_{0}=10.9033 \mathrm{keV}$ on the X-7A beam line at NSLS, Brookhaven National Laboratory, with corresponding data for $\left(\mathrm{Rb}_{2} \mathrm{O}\right)_{0.2} \bullet\left(\mathrm{GeO}_{2}\right)_{0.8}$. As in the neutron data shown in Fig. 1 , both glasses show a pronounced FSDP with $\mathrm{Q}_{1}=$ 1.5 and $1.9 \dot{A}^{-1}$ respectively for the two glasses. In addition, the $\left(\mathrm{Rb}_{2} \mathrm{O}\right)_{0.2^{\circ}}\left(\mathrm{GeO}_{2}\right)_{0.8} \mathrm{x}$-ray pattern shows a pronounced $E R O P$ at $\mathrm{Q}_{0}=0.9 \dot{A}^{1}$.

Comparison of the $\mathrm{x}$-ray and neutron intensities of the different peaks provides some evidence about their origins. We define a "bulk scattering fraction" as the contribution of the concentration-weighted scattering amplitude of an atom relative to the sum of all the atoms in the glass. In $\mathrm{GeO}_{2}$, the bulk scattering fractions for neutrons are 0.413 and 0.587 for Ge and $O$ respectively, while for $x$-rays they are 0.667 and 0.333 , respectively. The stronger predominance of the FSDP in the $x$-ray peak indicates that it is due primarily to Ge-Ge correlations, as is generally the case in oxide and chalcogenide 
glasses. ${ }^{11}$ In $\left(\mathrm{Rb}_{2} \mathrm{O}\right)_{0.2^{\bullet}}\left(\mathrm{GeO}_{2}\right)_{0.8}$, the bulk scattering fractions for neutrons are $0.527(\mathrm{O}), 0.331(\mathrm{Ge})$, and $0.143(\mathrm{Rb})$, whereas for $\mathrm{x}$-rays they are $0.262(\mathrm{O})$, $0.467(\mathrm{Ge})$ and $0.270(\mathrm{Rb})$. Putting these numbers into the expressions for the average structure factors, we find that correlations involving two metal atoms ( $\mathrm{Ge}$ or $\mathrm{Rb}$ ) are emphasized in the $\mathrm{x}$-ray structure factors compared with the neutron ones, while all those involving oxygen are de-emphasized. The strong predominance of the FSDP in the $x$-ray pattern indicates that, in the $\mathrm{Rb}$ containing glass, it is again due to $\mathrm{Ge}-\mathrm{Ge}$, and probably other metal-metal, correlations. Since the EROP is considerably weaker in $x$-ray diffraction data, the ERO may involve oxygen atoms or, alternatively, some of the metal-metal correlations may have a negative contribution to this peak.

To obtain more clues about the origin of the IRO and ERO in these glasses, anomalous $x$-ray scattering measurements were made near the $G e$ and $\mathrm{Rb}$ K-shell absorption edges. Raw diffraction data for the $\left(\mathrm{Rb}_{2} \mathrm{O}\right)_{0.2^{\bullet}}\left(\mathrm{GeO}_{2}\right)_{0.8}$ glass are shown in Fig. 3 for runs (a) 13.3 and $200 \mathrm{eV}$ from the Ge edge at $11.1036 \mathrm{keV}$, and (b) 19.3 and $300 \mathrm{eV}$ below the Rb edge at $15.2023 \mathrm{keV}$. It is seen that the FSDP has a positive derivative with respect to both scattering amplitudes (which increase as the energy is reduced below the edge), while the EROP has a positive amplitude with respect to the Ge amplitude but a negative one with respect to the $\mathrm{Rb}$ amplitude. From the bulk scattering factors defined above, it follows that

$$
\begin{aligned}
& d S(Q) / d f_{G e}=0.270 S_{R b G e}+0.467 S_{G e G e}+0.262 S_{G e O}, \\
& d S(Q) / d f_{R b}=0.270 S_{R b R b}+0.467 S_{R b G e}+0.262 S_{R b O},
\end{aligned}
$$

where the $S_{i j}(Q)$ are the Faber-Ziman partial structure factors. The positive derivatives for the FSDP indicate that other metal-metal correlations, in addition 
to the $\mathrm{Ge}-\mathrm{Ge}$ correlation which dominates in the pure $\mathrm{GeO}_{2}$, are contributing to the IRO in the rubidium germanate glass. The behavior of the EROP can be explained in terms of chemical ordering of the metal atoms if $S_{R b G e}$ is negative and $S_{R b R b}$ and $S_{G e G e}$ are positive. This is also consistent with a reduction in intensity of the peak in the $x$-ray pattern compared with the neutron pattern.

It is interesting to compare the behavior of the EROP with that of the peak at $Q_{2}=2.8 \AA$, which is due in the pure $\mathrm{GeO}_{2}$, and presumably in the rubidium germanate glass as well, to chemical ordering of the $\mathrm{Ge}$ and $\mathrm{O}$. In the Molecular Dynamics simulations of Vashishta et al. ${ }^{11}$ in $\mathrm{v}--\mathrm{SiO}_{2}$ (we are not aware of any equivalent work in $\mathrm{GeO}_{2}$ ), $\mathrm{S}_{\text {sio }}$ has a negative contribution to this peak and SsiSi and Soo positive contributions. The peak arises in all three partials from Coulomb oscillations in the partial pair correlation functions $g_{i j(}(r)$ with period $2 \pi / Q_{2} \sim 2.2 \AA$, in phase with $\sin \left(Q_{2} r\right)$ for gSisi and goo and out of phase for gsio We are proposing a similar origin for the EROP in terms of a chemical ordering of the $\mathrm{Rb}$ and Ge cations with a period $2 \pi / \mathrm{Q}_{0} \sim 7 \dot{\mathrm{A}}$.

EROP are observed in other oxide glasses as well. Gaskell et al..12 found an ordering of $\mathrm{Ca}$ cations in calcium silicate glass with a correlation length of $3.8 \dot{A}$, which may have a similar origin to the ERO we are describing, but the first peak in $S(Q)$ is at $Q=1.3 \dot{A}^{-1}$, a value more typical of the FSDP. Measurements of $\left(\mathrm{M}_{2} \mathrm{O}\right)_{0.2^{\bullet}}\left(\mathrm{SiO}_{2}\right)_{0.8}$ glasses by Hannon et al. ${ }^{13}$ do show an EROP at $Q_{0} \sim 1 \AA$ for $M=K$, but not Li. An EROP is also observed in recent measurements ${ }^{14}$ of $S(Q)$ for a glass made by fusing the archtypal wadeite, $\mathrm{K}_{2} \mathrm{ZrSi}_{3} \mathrm{O}_{9}$, where the $\mathrm{Si}$ is 6 -fold coordinated, showing that the existence of an EROP does not depend on a specific environment for the Si cation.

Table 1 shows the values of $Q_{0}, r_{1}$, and the mean interatomic spacing $d_{s}$ $\left[\rho^{-1}=(\pi / 6) d_{s}^{3}\right]$ for the $\mathrm{Rb}_{2} \mathrm{O}-\mathrm{GeO}_{2}$ glasses measured by us and the other glasses discussed above. Fig. 4 plots $Q_{1} d_{s}$ against $Q_{1} r_{1}$ for the same glasses 
and compares them with the same quantities for the FSDP and other peaks of various glasses. It can be seen that both the EROP and the FSDP lie in characteristic regions of this plot, separated from each each other and from the peaks at higher $Q$ due to chemical and topological ordering.

In summary, we have identified a new type of order in complex glasses which we call extended-range order, characterized by a diffraction peaks at values of $Q$ below those typical of the FSDP associated with intermediate-range order. From a comparison of neutron and $\mathrm{x}$-ray diffraction data and a careful study of anomalous $x$-ray scattering from rubidium germanate glass, we deduce that, at least in this glass, the EROP is associated with chemical ordering of the two cations with respect to each other.

This work was supported by the U.S. Department of Energy, Division of Materials Sciences, Office of Basic Energy Sciences, under Contract W--31109-ENG-38 We gratefully acknowledge the assistance of the Operations Staffs at IPNS, ISIS and NSLS.

\section{References}

1 S. R. Elliott, Nature 354, 445-452 (1991)

2. W. L. Konijnendijk and J. M. Stevels, J. Non-Cryst. Solids 18, 307-331 (1975)

3. F. L. Galeener, Solid State Commun. 44, 1037-1040 (1982)

4 P. M. Bridenbaugh, G. P. Espinosa, J. E. Griffiths, J. C. Phillips and J. P. Remeika, Phys. Rev. B20, 4140-4144 (1979)

5 D. L. Price, S. C. Moss, R. Reijers, M.-L. Saboungi and S. Susman, J. Phys.: Condens. Matter 1, 1005-1008 (1989)

6 S. C. Moss and D. L. Price, in Physics of Disordered Materials, ed. D. Adler, H. Fritzsche, S. R. Ovshinsky (Plenum, New York, 1985), pp. 77-95.

7 J. C. Phillips, J. Non-Cryst. Solids 43, 37 (1981).

8 S. R. Elliott, Phys. Rev. Lett. 76, 711-714 (1991)

9 V. N. Novikov and A. P. Sokolov, Solid State Commun. 77, 243-247 (1991); A. P. Sokolov, A. Kisliuk, M. Soltwisch, and D. Quitmann, Phys. Rev. Letters 69, 1540-1543 (1992). 
10 J. A. E. Desa, A. C. Wright and R. Sinclair, J. Non-Cryst. Solids 99, 276-288 (1988)

11P. Vashishta, R. K. Kalia, J. P .Rino, and I. Ebbsjo, Phys. Rev. B 41, 12197 12208(1990)

12 P. H. Gaskell, M. C. Eckersley, A. C. Barnes and P. Chieux, Nature 350, 675-677 (1991)

13 A. Hannon, B. Vessal and J. M. Parker, J. Non-Cryst. Solids, in press (1992).

14 A. J. G. Ellison and J. E. Dickinson, Jr., to be published. 
Table 1. $Q_{0}, r_{1}$, and $d s$ of glasses cited in the text.

\begin{tabular}{|c|c|c|c|}
\hline Glass & $\mathrm{Q}_{0} \mathrm{a}^{\mathrm{a}}$ & $r_{1} b$ & $d_{s} \mathrm{c}$ \\
\hline $\begin{array}{l}\left(\mathrm{Rb}_{2} \mathrm{O}\right)_{0.1} \cdot\left(\mathrm{GeO}_{2}\right)_{0.9} \\
\left(\mathrm{Rb}_{2} \mathrm{O}\right)_{0.2^{\circ}}\left(\mathrm{GeO}_{2}\right)_{0.8} \\
\left(\mathrm{Rb}_{2} \mathrm{O}\right)_{0.33^{\circ}\left(\mathrm{GeO}_{2}\right)_{67}}\end{array}$ & $\begin{array}{l}1.74 \\
1.63 \\
1.68\end{array}$ & $\begin{array}{l}1.74 \\
1.77 \\
1.74\end{array}$ & $\begin{array}{l}3.06 \\
2.95 \\
3.12\end{array}$ \\
\hline$\left(\mathrm{K}_{2} \mathrm{O}\right)_{0.2}\left(\mathrm{ZrO}_{2}\right)_{0.2}\left(\mathrm{SiO}_{2}\right)_{0.6}$ & 1.85 & 1.61 & 3.70 \\
\hline$\left(\mathrm{K}_{2} \mathrm{O}\right)_{0.2}\left(\mathrm{SiO}_{2}\right)_{0.8}$ & 1.28 & 1.60 & 2.80 \\
\hline
\end{tabular}

aPosition of EROP

bNearest-neighbor distance

cMean interatomic spacing 
Figure 1. The average structure factor $\mathrm{S}(\mathrm{Q})$ of $\mathrm{Rb}_{2} \mathrm{O}-\mathrm{GeO}_{2}$ glasses, measured by neutron diffraction.

Figure 2. X-ray diffraction patterns for $\mathrm{GeO} 2(* * *)$ and $\left(\mathrm{Rb}_{2} \mathrm{O}\right)_{0.2}\left(\mathrm{GeO}_{2}\right)_{0.8}$ glasses at $E 0=10.9033 \mathrm{keV}$.

Figure 3. X-ray diffraction patterns for $\left(\mathrm{Rb}_{2} \mathrm{O}\right)_{0.2^{\circ}}\left(\mathrm{GeO}_{2}\right)_{0.8}$ glass. (a) Data taken near the Ge $K$ absorption edge $\left(E_{0}=11.1036 \mathrm{keV}\right)$, "**: $E_{0}-E=$ $200 \mathrm{eV} ;{ }^{* * *}: E_{0}-E=13.3 \mathrm{eV}$. (b) Data taken near the Rb K absorption edge $\left(E_{0}=15.2023 \mathrm{keV}\right)$, "**: $E_{0}-E=300 \mathrm{eV} ;{ }^{* \star *}: E_{0}-E=19.3 \mathrm{eV}$.

Figure 4. $Q_{1} d s$ vs. $Q_{1} r_{1}$, where $d s$ is the mean interatomic spacing and $r_{1}$ is the nearest-neighbor distance. 


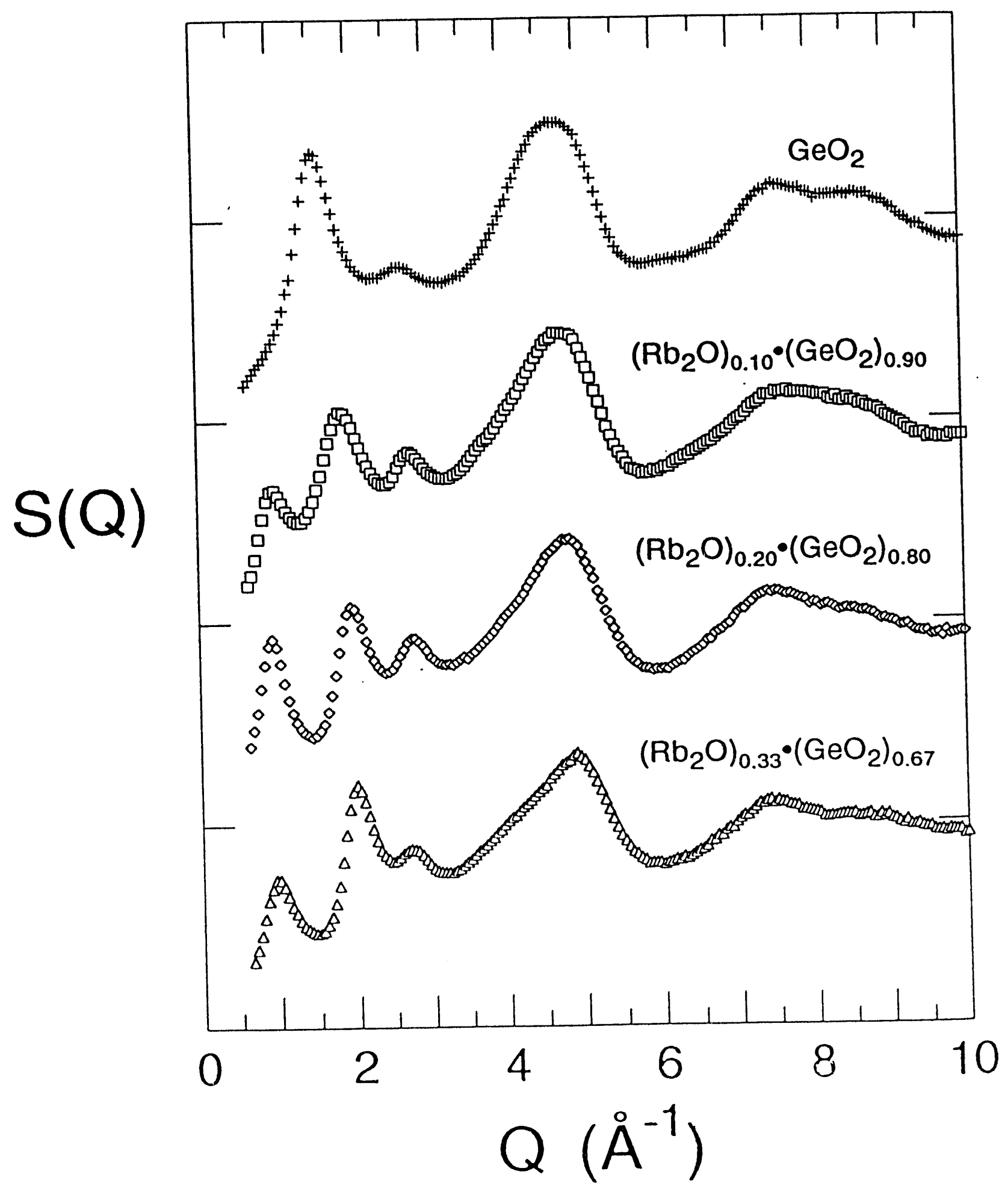

rig 1 


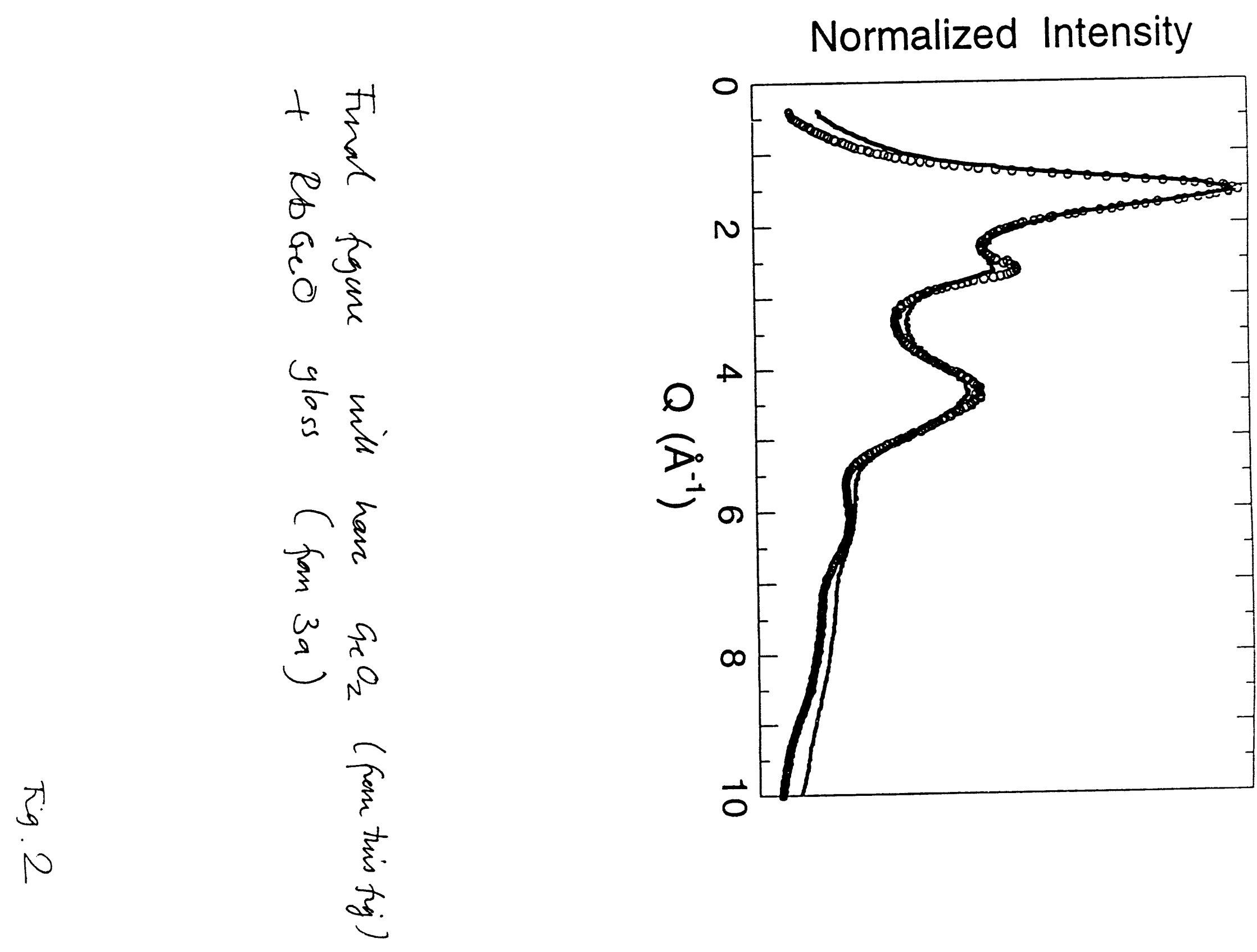




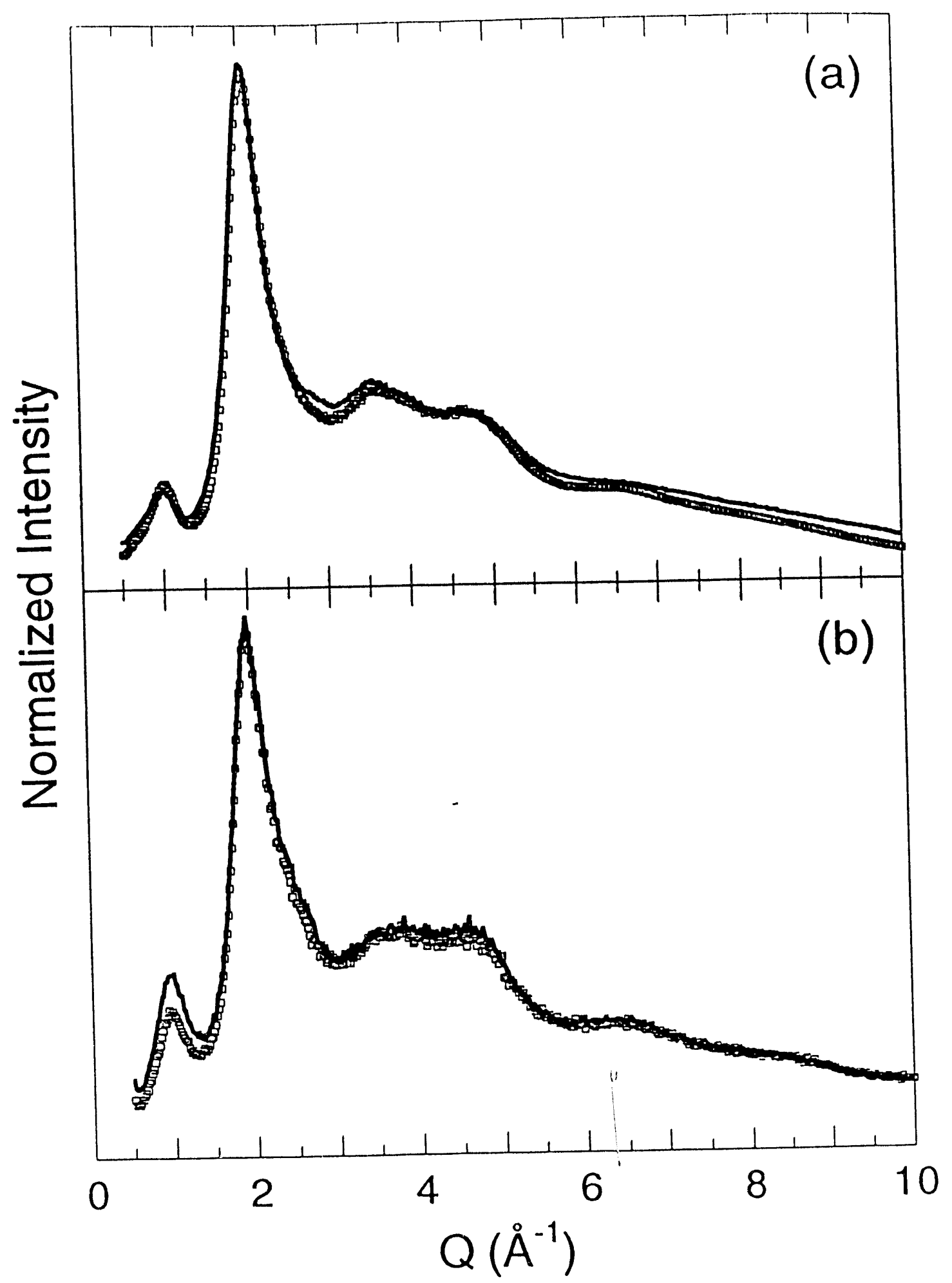

Fig 3 


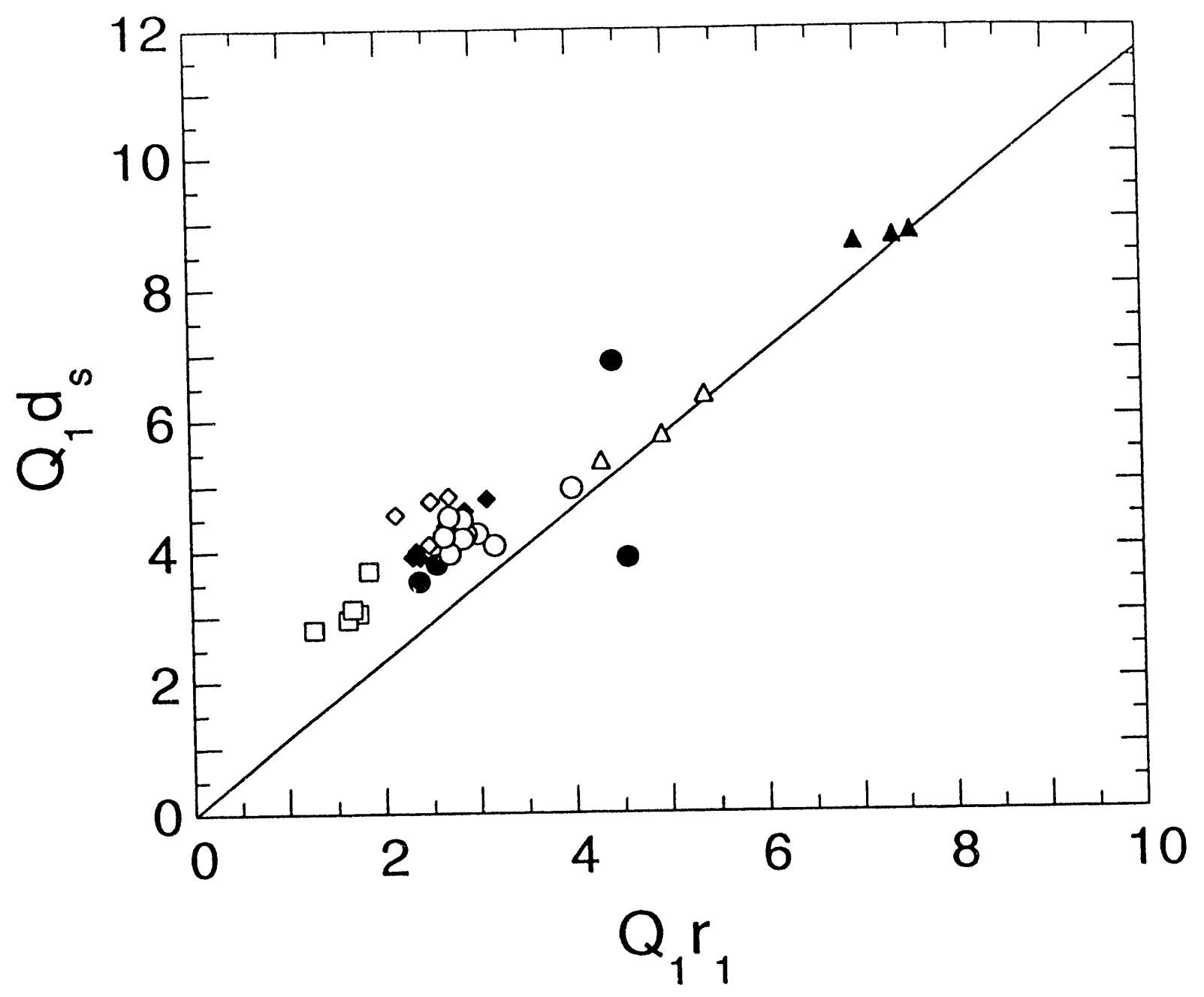


Table 1. $Q_{0}, r_{1}$, and $d s$ of glasses cited in the text.

\begin{tabular}{|c|c|c|}
\hline Glass & $Q_{0}{ }^{a}$ & $r_{1}^{b}$ \\
\hline $\begin{array}{l}\left(\mathrm{Rb}_{2} \mathrm{O}\right)_{0.1} \bullet\left(\mathrm{GeO}_{2}\right)_{0.9} \\
\left(\mathrm{Rb}_{2} \mathrm{O}\right)_{0.2} \cdot\left(\mathrm{GeO}_{2}\right)_{0.8} \\
\left(\mathrm{Rb}_{2} \mathrm{O}\right)_{0.33^{\circ}}\left(\mathrm{GeO}_{2}\right)_{67}\end{array}$ & $\begin{array}{l}1.74 \\
1.63 \\
1.68\end{array}$ & $\begin{array}{l}1.74 \\
1.77 \\
1.74\end{array}$ \\
\hline$\left(\mathrm{K}_{2} \mathrm{O}\right)_{0.2}\left(\mathrm{ZrO}_{2}\right)_{0.2}\left(\mathrm{SiO}_{2}\right)_{0.6}$ & 1.85 & 1.61 \\
\hline$\left(\mathrm{K}_{2} \mathrm{O}\right)_{0.2}\left(\mathrm{SiO}_{2}\right)_{0.8}$ & 1.28 & 1.60 \\
\hline
\end{tabular}


Table 1. $Q_{0}, r_{1}$, and $d s$ of glasses cited in the text.

\begin{tabular}{llll}
\cline { 1 - 2 } \multicolumn{1}{c}{ Glass } & $\mathrm{Q}_{0}^{\mathrm{a}}$ & $\mathrm{r}_{1}^{\mathrm{b}}$ & $d_{s} \mathrm{c}$ \\
\cline { 1 - 2 }$\left(\mathrm{Rb}_{2} \mathrm{O}\right)_{0.1} \cdot\left(\mathrm{GeO}_{2}\right)_{0.9}$ & 1.74 & 1.74 & 3.06 \\
$\left(\mathrm{Rb}_{2} \mathrm{O}\right)_{0.2^{\bullet}\left(\mathrm{GeO}_{2}\right)_{0.8}}$ & 1.63 & 1.77 & 2.95 \\
$\left(\mathrm{Rb}_{2} \mathrm{O}\right)_{0.33^{\circ}\left(\mathrm{GeO}_{2}\right)_{67}}$ & 1.68 & 1.74 & 3.12 \\
$\left(\mathrm{~K}_{2} \mathrm{O}\right)_{0.2}\left(\mathrm{ZrO}_{2}\right)_{0.2}\left(\mathrm{SiO}_{2}\right)_{0.6}$ & 1.85 & 1.61 & 3.70 \\
$\left(\mathrm{~K}_{2} \mathrm{O}\right)_{0.2}\left(\mathrm{SiO}_{2}\right)_{0.8}$ & 1.28 & 1.60 & 2.80 \\
\hline
\end{tabular}

aposition of EROP

bNearest-neighbor distance

cMean interatomic spacing 
Table 1. $Q_{0}, r_{1}$, and $d s$ of glasses cited in the text.

\begin{tabular}{lccc}
\hline \multicolumn{1}{c}{ Glass } & $\mathrm{Q}_{0}^{\mathrm{a}}$ & $\mathrm{r}_{1}^{\mathrm{b}}$ & \multicolumn{1}{c}{$d_{s}^{\mathrm{c}}$} \\
\cline { 1 - 3 }$\left(\mathrm{Rb}_{2} \mathrm{O}\right)_{0.1} \cdot\left(\mathrm{GeO}_{2}\right)_{0.9}$ & 1.74 & 1.74 & 3.06 \\
$\left(\mathrm{Rb}_{2} \mathrm{O}\right)_{0.2} \cdot\left(\mathrm{GeO}_{2}\right)_{0.8}$ & 1.63 & 1.77 & 2.95 \\
$\left(\mathrm{Rb}_{2} \mathrm{O}\right)_{0.33^{\bullet}\left(\mathrm{GeO}_{2}\right)_{67}}$ & 1.68 & 1.74 & 3.12 \\
$\left(\mathrm{~K}_{2} \mathrm{O}\right)_{0.2}\left(\mathrm{ZrO}_{2}\right)_{0.2}\left(\mathrm{SiO}_{2}\right)_{0.6}$ & 1.85 & 1.61 & 3.70 \\
$\left(\mathrm{~K}_{2} \mathrm{O}\right)_{0.2}\left(\mathrm{SiO}_{2}\right)_{0.8}$ & 1.28 & 1.60 & 2.80 \\
\hline
\end{tabular}

aposition of EROP

bNearest-neighbor distance

cMean interatomic spacing 


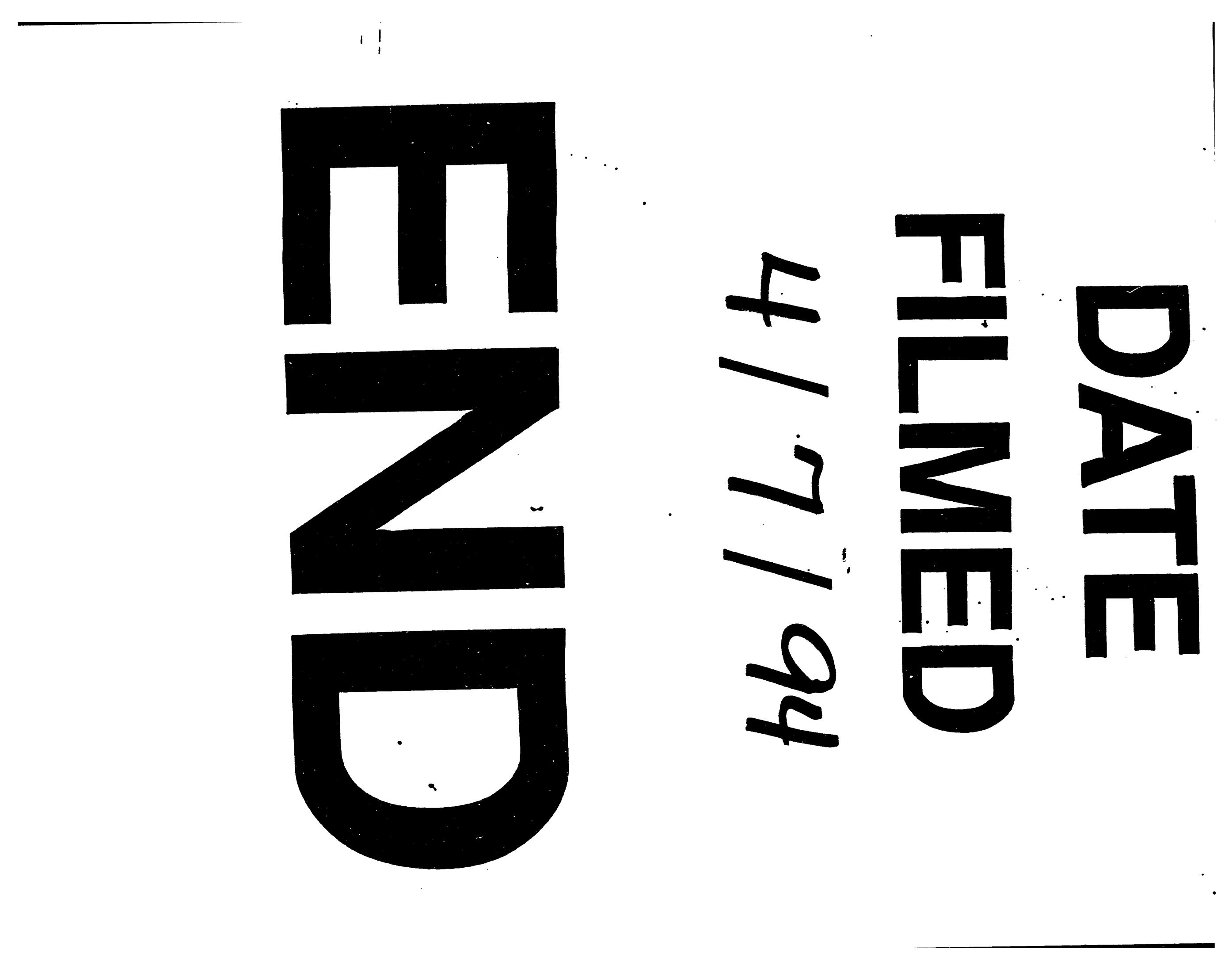


